\title{
A IMPORTÂNCIA DO ENFERMEIRO EM CENTROS DE TRANSPLANTE HEPÁTICO
}

\author{
The importance of nurses in liver transplant centers
}

Francielen Cristina Lopes Genova, Silvia Ricci Tonelli

\section{RESUMO}

O transplante hepático é um procedimento complexo realizado em grandes hospitais, decorrente de alterações funcionais em todo o organismo, demandando completa infraestrutura hospitalar e equipe multidisciplinar altamente treinada. A partir dessa informação, objetivou-se realizar uma síntese e discussão das publicações científicas acerca das ações do enfermeiro frente ao paciente na lista de espera para transplante hepático, apontar as principais patologias que o leva ao transplante, as ações do cuidado de Enfermagem implementadas ao paciente em fila de espera, abordando os aspectos sociais, físicos e psicossociais e descrever os cuidados de preparo no préoperatório, visando a melhor evolução do paciente a ser transplantado. A presente revisão bibliográfica foi elaborada, contemplando livros, artigos científicos, revistas e sites governamentais, nas seguintes bases de dados: LILACS, SCIELO e PubMed publicados entre 2005 a 2015. A partir de 40 artigos encontrados, foram escolhidos nove relacionados ao tema proposto, concluindo que o enfermeiro em unidades transplantadoras é responsável pelo gerenciamento da assistência, atividades assistenciais, administrativas, ensino e pesquisa, sendo de extrema necessidade a criação de protocolos e manuais onde serão esclarecidas aos pacientes quaisquer dúvidas relacionadas a esse processo, atuando precocemente para, assim, gerar bons resultados no pós-operatório.

Descritores: Transplante Hepático; Cuidados de Enfermagem; Fígado

\section{Instituição:}

Faculdade de Enfermagem da Pontifícia Universidade Católica de Campinas, Campinas/SP - Brasil

\section{Correspondência:}

Francielen Lopes

Rua Augusta Diogo Ayala, 21, Cond. Araucária, Sumaré/SP

Tel.: (19) 98706-9501

E-mail: frncielenlopesg@hc.unicamp.br

\section{INTRODUÇÃO}

Segundo dados da Organização Mundial de Saúde (OMS), 20 pessoas por milhão de habitantes precisam ser submetidas a transplante hepático a cada ano numa determinada região, sendo o Nordeste brasileiro uma região com população superior a 45 milhões de indivíduos. Assim, estima-se que mais de 900 pessoas deveriam ser submetidas a transplante hepático anualmente. ${ }^{1}$

O transplante hepático é um procedimento complexo realizado em hospitais de grande porte, demandando completa infraestrutura hospitalar e equipe multidisciplinar altamente treinada, decorrente de alterações funcionais em todo o organismo. 
O fígado é a maior glândula do corpo e está localizado atrás das costelas, na porção superior direita da cavidade abdominal. Possui formato de prisma; sua coloração é vermelho escuro, tendendo ao marrom. Pesa cerca de $1.500 \mathrm{~g}$ e é dividido em quatro lobos. Recebe sangue venoso vindo, na maior parte, do trato gastrintestinal através de uma grande veia: a veia porta. As principais funções do fígado são: metabolizar a glicose, proteína e medicamentos, armazenar vitamina e ferro, formação da bile e coagulação sanguínea. ${ }^{2}$

Segundo o Ministério da Saúde, o transplante de fígado só é indicado para pessoas com doenças hepáticas agudas ou crônicas irreversíveis e progressivas. A hepatite crônica por vírus da hepatite $\mathrm{C}$ (VHC) e cirrose alcoólica representam cerca de $50 \%$ das etiologias que levam pacientes adultos ao transplante. $\mathrm{Na}$ população pediátrica, as principais indicações de transplante hepático são: atresia (obstrução progressiva sem causa definida) das vias biliares (57\%), seguida das doenças metabólicas (19\%). ${ }^{2}$

A indicação para transplante de fígado tem por objetivo aumentar o tempo de vida do paciente, devolvendo-o para a sociedade com capacidades físicas, motoras e intelectuais. Desde o início da ciclosporina nos anos 80, resultados cada vez melhores vêm sendo observados. Para que possamos eleger um paciente candidato a transplante hepático é necessário conhecer sua história, bem como a patologia atual e seus agravantes para que possamos identificar as contraindicações ao procedimento e a existência de fatores que podem piorar o prognóstico em curto ou longo prazo. É indicado transplante hepático para pacientes portadores de insuficiência hepática crônica, com expectativa de vida inferior a $20 \% .^{3}$

As principais doenças do fígado são: cirrose hepática: doença crônica caracterizada pela substituição do tecido hepático normal pela fibrose difusa, a qual rompe a estrutura e a função do fígado; hepatite viral: infecção viral sistêmica em que a necrose e a inflamação das células hepáticas produzem um grupo peculiar de alterações clínicas, bioquímicas e celulares. Até o momento, cinco tipos definidos de hepatite viral foram identificados: hepatites A, B, C, D e E; hipertensão porta e ascite: alterações circulatórias dentro do fígado comprometido, produzindo hemorragias gastrointestinais graves e acentuada retenção de sódio e líquido; deficiências nutricionais, resultado da incapacidade das células hepáticas lesionadas de metabolizar determinadas vitaminas responsáveis pelo comprometimento funcional dos sistemas nervosos central e periférico e pelas tendências anormais para o sangramento; encefalopatia hepática: acúmulo de amônia no soro devido ao metabolismo proteico comprometido pelo fígado lesionado. ${ }^{2}$
De acordo com a Aliança Brasileira pela Doação de Órgãos e Tecidos (ADOTE), no dia 29 de maio de 2006 o Ministério da Saúde publicou a Portaria 1160, que modifica os critérios de distribuição de fígado de doadores falecidos para transplante, implantando o critério de gravidade de estado clínico do paciente, desenvolvido na Clínica Mayo e modificado pela United Network for Organ Sharion - UNOS, um modelo quantitativo que estima o risco da mortalidade de uma pessoa com doença hepática terminal com base em exames laboratoriais.

Para aferir o critério de gravidade, foi adotado o sistema MELD e PELD.

MELD - Model for End-stage Liver Disease - é uma variação numérica de 6 (menor gravidade) a 40 (maior gravidade), usado para quantificar a urgência de transplante de fígado em candidatos com idade igual a doze anos ou mais. É uma estimativa do risco de óbito, caso não seja realizado o transplante nos próximos três meses. ${ }^{4}$

O valor MELD é calculado por uma fórmula a partir do resultado de três exames laboratoriais de rotina, ou seja: Bilirrubina, que mede a eficiência do fígado em excretar bile; Creatinina, medida da função renal e RNI - Relação Normalizada Internacional - são medidas laboratoriais para avaliar a via extrínseca da coagulação, que mede a função do fígado com respeito à produção desses fatores. $^{4}$

PELD - Pediatric End-stage Liver Disease - é uma escala aplicada em crianças menores de doze anos, com valores similares ao MELD, levando em conta diferentes exames laboratoriais que mede a eficiência do fígado. (op cit.)

Segundo Mies, ${ }^{5}$ a primeira tentativa de transplante de fígado em humanos foi realizada nos Estados Unidos, em 1963, em Denver Colorado, por Thomas Starzl, que tentou novamente o transplante em uma criança de três anos de idade; a criança foi operada e, durante a cirurgia, apresentou alterações da coagulação sanguínea e acabou evoluindo para óbito no intraoperatório por sangramento; desde então, foi aumentando o número de transplante naquela região e espalhando-se por todo o continente. Pretendia-se conseguir apoio da população para a doação de órgãos e aumentar o número dos beneficiados com esse procedimento. Em 1978, ocorreu um fato importante para o desenvolvimento dos programas de transplantes, que foi o aparecimento de uma nova droga imunossupressora: a ciclosporina.

Segundo Silva, ${ }^{6}$ o primeiro transplante de fígado no Brasil foi realizado em 1968, pelo Prof. Marcel C.C Machado, em um paciente com carcinoma hepatocelular que teve óbito precoce. Segundo Garcia, o primeiro transplante 
de fígado do Ceará foi realizado em maio de 2002; já em setembro de 1991, segundo Boin, foi realizado o primeiro transplante na cidade de Campinas.

\section{MATERIAL E MÉTODOS}

A Revisão Integrativa (RI) é uma forma de estruturação Este estudo foi realizado por meio de revisão integrativa, visto que esta possibilita sumarizar pesquisas já realizadas e obter conclusões a partir de um tema de interesse.

Para guiar a presente revisão integrativa, formulou-se a seguinte questão norteadora: Quais são as evidências científicas de que a participação do enfermeiro com pacientes na fila do transplante hepático contribui ou gera falta de orientação do paciente?

O levantamento bibliográfico foi realizado acessando as bases eletrônicas de dados da Literatura LatinoAmericana e do Caribe em Ciências da Saúde (LILACS), Scientific Electronic Library Online (SciELO), livros e sites governamentais contemplando obras publicados entre 2005 a 2015, com o critério de inclusão de artigos publicados na íntegra, em língua portuguesa, usando os seguintes descritores: fígado, transplante de fígado, cuidados de Enfermagem ao transplantado hepático e fila de transplante. A partir de 40 artigos encontrados, foram escolhidos oito relacionados ao tema proposto.

\section{RESULTADOS}

A coleta inicial de pesquisa com os descritores totalizou 79 artigos que, após a análise oferecida por seus resumos/abstracts e títulos, foram filtrados para o total de 22 publicações. Estas, após leitura integral e confrontamento metodológico, resultaram em oito artigos que responderam aos critérios de inclusão, propostos com suficiência de retorno aos objetivos do estudo, abordando de forma suficiente os impactos, ou algum prisma de impactos da presença do psicólogo no espaço das CIHDOTT, conforme descrito na Tabela 1.

\section{DISCUSSÃO}

Instruções aos pacientes em lista de espera para transplante hepático são fundamentais para o sucesso do transplante, repercutindo em boa recuperação, porém, a literatura nessa área ainda é escassa.

Pacientes candidatos ao transplante hepático devem ter ciência de todos os processos a serem enfrentados durante a espera do órgão, como exames diagnósticos e cuidados que se estenderão por toda a vida, e cabe ao enfermeiro a educação e acompanhamento desses pacientes durante o processo, ressaltando cuidados e intervenções capazes de evitar a progressão dos danos no fígado, bem como alterações do regime dietético, restrição de fluidos, atenção aos sinais e sintomas que requerem avaliação imediata, dentre outras. ${ }^{7}$

O mesmo autor, ${ }^{8}$ entre todos os benefícios do processo de educação em saúde para os candidatos, ressaltase o aumento da satisfação e da qualidade de vida, melhoria da continuidade dos cuidados no domicílio, redução da ansiedade e das possíveis complicações, melhor aderência ao plano de tratamento proposto, aumento da independência e empoderamento.

Para Mendes, ${ }^{9}$ o cuidado da Enfermagem em transplante de fígado evidenciou publicações sobre os cuidados para o preparo do paciente, prevenção de lesões, importância de um sistema de documentação, prevenção e detecção precoce de complicações, ensino da terapêutica imunossupressora, ensino ao paciente e atuação do enfermeiro no pré, intra e pós-operatório, bem como sobre o papel desse profissional no suporte nutricional e emocional de pacientes e familiares, dentre outras, ressaltando a importância do processo de Enfermagem, bem como a criação de protocolos de atendimento a esses pacientes.

Segundo Sasso et al, ${ }^{7}$ o conhecimento dos pacientes candidatos ao transplante hepático mostra que, em relação às complicações mais comuns da cirrose hepática, apenas um $(7,7 \%)$ paciente não teve qualquer dúvida. A maior parte das dúvidas foi relacionada à ascite, frequência na incidência de infecções (devido à imunossupressão natural do cirrótico), e à frequente insuficiência renal que se instala nesses pacientes.

No que diz respeito ao doador, nove $(69,2 \%)$ pacientes apresentaram dúvidas, sendo que as principais eram em relação à possibilidade de retornar à vida após a morte encefálica, sobre o sexo do doador ser o mesmo do receptor, consentimento da família do doador para a doação e qualquer tipo de morte, mesmo fora do hospital ser passível de doação. (op cit.)

Essas, dentre muitas dúvidas apresentadas pelos candidatos foram esclarecidas pela autora do estudo, pontuando, assim, a necessidade de um profissional de Enfermagem qualificado para fornecer demais instruções.

Segundo Carvalho ${ }^{10}$ e Marandola ${ }^{11}$ o sucesso dos transplantados hepáticos depende do ensino ao paciente com relação ao quadro atual, sendo fundamental nessa etapa a participação dos familiares, com o enfermeiro atuando como fonte educadora, esclarecendo dúvidas durante sua permanência na unidade. 
Tabela 1 - Caracterização das publicações

\begin{tabular}{|c|c|c|c|}
\hline Nome do Artigo & Ano & Autor & Síntese \\
\hline $\begin{array}{l}\text { Transplante de fígado: resultados } \\
\text { de aprendizagem de pacientes que } \\
\text { aguardam a cirurgia }\end{array}$ & 2005 & $\begin{array}{l}\text { Karina Dal Sasso } \\
\text { Cristina Maria Galvão } \\
\text { Orlando de Castro e Silva Jr } \\
\text { Alex Vianey Callado França }\end{array}$ & $\begin{array}{l}\text { Descreve os resultados de aprendizagem da experiência } \\
\text { de implementação de estratégias de ensino com os } \\
\text { pacientes que serão submetidos a transplante de fígado. }\end{array}$ \\
\hline $\begin{array}{l}\text { Diagnóstico de Enfermagem de } \\
\text { pacientes em pós-operatório de } \\
\text { transplante hepático por cirrose etílica } \\
\text { e não-etílica }\end{array}$ & 2007 & $\begin{array}{l}\text { Daclé Vilma Carvalho } \\
\text { Márcia Eller Miranda Salviano } \\
\text { Roberta Azevedo Carneiro Fabrícia } \\
\text { Madalena Meira Santos }\end{array}$ & $\begin{array}{l}\text { Este estudo analisou } 37 \text { históricos de Enfermagem de } \\
\text { pacientes transplantados no período de primeiro de } \\
\text { setembro de } 2005 \text { a } 30 \text { de setembro de } 2006 \text {. }\end{array}$ \\
\hline $\begin{array}{l}\text { Necessidades de informação de } \\
\text { candidatos ao transplante de fígado: o } \\
\text { primeiro passo } \\
\text { do processo ensino-aprendizagem }\end{array}$ & 2008 & $\begin{array}{l}\text { Karina Dal Sasso Mendes; } \\
\text { Fabiana Murad Rossin; } \\
\text { Luciana da Costa Ziviani; } \\
\text { Orlando de Castro-e-Silva; } \\
\text { Cristina Maria Galvão }\end{array}$ & $\begin{array}{l}\text { Identifica as necessidades de informação de candidatos } \\
\text { em fila de espera para transplante de fígado. Os } \\
\text { resultados evidenciaram que o conhecimento de } \\
\text { informações que o candidato ao transplante de fígado } \\
\text { precisa é relevante para o planejamento do processo } \\
\text { ensino-aprendizagem. }\end{array}$ \\
\hline $\begin{array}{l}\text { Transplante de fígado: evidências para o } \\
\text { cuidado de Enfermagem. }\end{array}$ & 2008 & $\begin{array}{l}\text { Karina Dal Sasso Mendes } \\
\text { Cristina Maria Galvão }\end{array}$ & $\begin{array}{l}\text { Publicações sobre os cuidados de Enfermagem para } \\
\text { preparo do paciente, prevenção de lesões, importância } \\
\text { de um sistema de documentação, prevenção e deteç̧ão } \\
\text { precoce de complicações, ensino da terapêutica } \\
\text { imunossupressora, ensino ao paciente e atuação do } \\
\text { enfermeiro no pré, intra e pós-operatório. }\end{array}$ \\
\hline $\begin{array}{l}\text { Consulta de Enfermagem ao paciente } \\
\text { em pré-transplante de fígado: laboração } \\
\text { de um protocolo. }\end{array}$ & 2001 & $\begin{array}{l}\text { Paula Garcia Marandola, } \\
\text { Selme Silqueira de Matos, } \\
\text { Ana Lúcia de Mattia, } \\
\text { Adelaide de Mattia Rocha, } \\
\text { Juscélia Schittini da Silva, } \\
\text { Michelly Keesen Batista Resende }\end{array}$ & $\begin{array}{l}\text { Foi realizada a elaboração do protocolo de consulta de } \\
\text { Enfermagem com abordagens como: o candidato, lista } \\
\text { de espera, exames realizados, acompanhante, hábitos de } \\
\text { vida após o transplante, como proceder à chamada para } \\
\text { realização do transplante, procedimento cirúrgico, alta } \\
\text { hospitalar e complicações mais frequentes. }\end{array}$ \\
\hline $\begin{array}{l}\text { Sentimentos e expectativas de pacientes } \\
\text { candidatos ao transplante de fígado. }\end{array}$ & 2001 & $\begin{array}{l}\text { Maria Isis Freire de Aguiar, } \\
\text { Violante Augusta Batista Braga }\end{array}$ & $\begin{array}{l}\text { Investiga os sentimentos e expectativas de } \\
\text { pacientes portadores de doenças hepáticas crônicas, } \\
\text { candidatos ao transplante hepático, concluindo que toda } \\
\text { vivência, manifestações clínicas e período de espera } \\
\text { pelo transplante são permeados por uma mistura de } \\
\text { sentimentos e reações. }\end{array}$ \\
\hline $\begin{array}{l}\text { Excesso de peso em pacientes } \\
\text { submetidos ao transplante hepático }\end{array}$ & 2013 & $\begin{array}{l}\text { Lucilene Rezende Anastácio, } \\
\text { Michel C. de Angelis Pereira, } \\
\text { Eduardo G. Vilela, } \\
\text { Agnaldo S. Lima, } \\
\text { Maria Isabel T. D. Correia. }\end{array}$ & $\begin{array}{l}\text { Descreve a incidência e prevalência do excesso de peso, } \\
\text { sobrepeso e obesidade pós-transplante hepático e as } \\
\text { consequências associadas a ele, apontando algumas. }\end{array}$ \\
\hline $\begin{array}{l}\text { Intervenção educativa para candidatos } \\
\text { ao transplante de fígado }\end{array}$ & 2013 & $\begin{array}{l}\text { Karina Dal Sasso Mendes, } \\
\text { Orlando de Castro e Silva Junior, } \\
\text { Luciana da Costa Ziviani, } \\
\text { Fabiana Murad Rossin, } \\
\text { Márcia Maria Fontão Zago, } \\
\text { Cristina Maria Galvão. }\end{array}$ & $\begin{array}{l}\text { Analisa o conhecimento de candidatos sobre o } \\
\text { processo de transplante de fígado antes e depois da } \\
\text { implementação de intervenção educativa, evidenciando } \\
\text { ganho cognitivo significativo após a intervenção. }\end{array}$ \\
\hline
\end{tabular}

Os dados da Tabela 1 evidenciam que 44,4\% das publicações ocorreram entre os anos 2005 e 2010,55,6\% de 2010 a 2015, em revistas de Enfermagem indexadas na base de dados da SCIELO. 
Mendes, ${ }^{8}$ afirma que a aprendizagem é o processo que permite aos indivíduos modificar seu comportamento permanentemente. $O$ aprendizado acontece quando a pessoa responde e recebe estímulo do seu ambiente externo. Quando se observa a alteração no desempenho do aprendiz, é notório que a aprendizagem ocorreu; já Marandola,${ }^{11}$ afirma que ensinar é transmitir o conhecimento e educar é transmitir os valores necessários ao convívio, manutenção e desenvolvimento da sociedade como um todo. O ensino na Enfermagem é um ensino agregado de valor, pois tem a finalidade de promover mudanças de hábitos tanto no paciente quanto na família e comunidade.

Segundo Marandola, ${ }^{11}$ e Aguiar, ${ }^{12}$ para a obtenção de um estilo de vida independente após o transplante hepático, o enfermeiro deve educar o paciente quanto aos seguintes assuntos: nutrição, medicamentos, monitorização dos sinais vitais, registro de informações, adequação a atividades físicas, atenção aos sinais de infecção, rejeição ou quaisquer manifestações clínicas. O ensino promove o desenvolvimento de habilidades cognitivas, psicomotoras e atitudinais, com as quais os pacientes e seus familiares podem garantir o sucesso e continuidade do cuidado, promovendo assim uma participação ativa no tratamento.

A avaliação do estado nutricional deve ser realizada minuciosamente em pacientes portadores de hepatopatias crônicas antes da realização do transplante, pois permite à equipe de Enfermagem diagnosticar importantes desvios e proporciona a aplicação de medidas de correção capazes de melhorar o prognóstico e diminuir as chances de complicações pós-operatórias, especialmente quando se pretende submeter tais pacientes ao recurso heroico do transplante hepático. ${ }^{9}$

Segundo Anastácio, ${ }^{13}$ estudos têm apontado que a obesidade, tanto do doador quanto do receptor, tem grande influência sobre os resultados operatórios. Pacientes pré-obesos obtêm grande probabilidade de, em seguida à operação, desenvolverem disfunção primária e função retardada do enxerto, aumentando o risco de morte, considerando que pacientes submetidos ao transplante hepático experimentam ganho de peso excessivo, principalmente no primeiro ano pós-transplante aumentando com o passar dos anos, sendo que o excesso de peso e a obesidade pós-transplante hepático também estão associados a diversas consequências como: esteatose hepática, esteatopatite, diabetes, hipertensão, dislipidemias e doenças cardiovasculares; surge então a necessidade de implementação de programas de prevenção de ganho de peso visando acompanhamento e educação dos pacientes em fila de espera para transplante hepático.

Segundo Aguiar e Braga, ${ }^{12}$ a espera do transplante traz consigo muitas expectativas e desordens emocionais no paciente como medo, receio, dúvidas, ansiedade relacionada à cirurgia e seus riscos. Afirmam também, que alterações psicológicas podem aparecer nesse momento, em virtude do mal funcionamento do fígado ou das complicações que demandam longo tempo de internação hospitalar. É nesse momento que a Enfermagem deve ser interdisciplinar com o campo de saúde mental, visando minimizar a dor e o sofrimento, atendendo as suas necessidades, sejam emocionais, culturais, biológicas ou sociais.

\section{CONSIDERAÇÕES FINAIS}

Após a elaboração deste estudo, concluímos que são inúmeras as patologias que levam o paciente ao transplante de fígado, portanto, a atuação do enfermeiro nos programas de transplante é essencial e relevante. Esses profissionais são responsáveis pelo gerenciamento da assistência prestada aos pacientes e seus familiares, praticando atividades assistenciais, administrativas, de ensino e pesquisa, sendo, então, importantes para o sucesso do transplante de fígado em todas as suas etapas, sendo, também, de extrema necessidade, a criação de protocolos e manuais onde serão esclarecidas ao paciente quaisquer dúvidas relacionadas a esse processo.

Portanto, entendemos que é de suma importância a atuação precoce do enfermeiro e o desenvolvimento de pesquisas e/ou a utilização de seus resultados para fundamentar a prática clínica e, nesse cenário, a prática baseada em evidências tem muito a oferecer. 


\section{ABSTRACT}

Purpose: Liver transplantation is a complex procedure performed in large hospitals demanding a complete hospital infrastructure and a highly trained multidisciplinary team due to functional changes throughout the body. From such information the aim was to achieve a synthesis and discussion of scientific publications on the actions of the nurse for patients on the waiting list for liver transplantation, indicating the main pathologies leading to transplant, nursing care actions implemented patient in the queue, addressing social, physical and psychosocial issues and describing the preparation of preoperatively care aiming better outcomes in patients to be transplanted. This literature review was prepared by covering books, papers, magazines and government sites in the following databases: LILACS, SciELO and PubMed published from 2005 to 2015 . From 40 articles, nine were selected related to the proposed theme. It was concluded that the nurse in transplanters units is responsible by managing the care, welfare, administrative, teaching and research activities, and the need to create protocols and manuals to clarify to patients any questions related to the process, in an early action to generate good post-surgery results.

Keywords: Liver transplantation; Nursing Care; Liver.

\section{REFERÊNCIAS}

1. Lacerda CM, Melo PSV, Lucena O, Almeida HM, Pereira LB. Liver transplantation in an university hospital in Recife: Initial results. Rio de Janeiro Rev Col Bras Cir. 2003 Jan/Fev;30(1):29-33

2. Ministério da Saúde. Portal da saúde. FÍGADO. Brasília. DF. [Acesso em 30 abr 2016]. Disponível em: http:// portalms.saude.gov.br/acoes-e-programas/doacaotransplantes-de-orgaos/figado

3. Castro-e-Silva O Jr, Sankarankutty AK, Oliveira GR, Pacheco E, Ramalho FS, Sasso KD, et al. Transplante de fígado: indicação e sobrevida. Acta Cir. Bras. 2002;17(3):83-91.

4. Aliança Brasileira pela Doação de Órgãos e Tecidos. Transplante de fígado: o critério de gravidade clínica com base no modelo meld/peld. Pelotas/RS. [Acesso em 28 mai 2016] Disponível em: http://www.adote.org.br/calculadora-meld-peld.

5. Mies S. Transplante de fígado. São Paulo. Rev. Assoc Med Bras. 1998;44(2):127-34.

6. Silva MRA. Um retrato do Transplante Hepático no Brasil. Ver Soc Bras de Hepatologia. 2013(Mar);4-7.

7. Sasso KD, Galvão CM, Castro-e-Silva O Jr, França AVC. Transplante de fígado: resultados de aprendizagem de pacientes que aguardam a cirurgia. Rev Latino-Am. Enfermagem 2005;13(4):481-8.
8. Sasso KD, Galvão CM, Castro-e-Silva O Jr, Ziviani LC, Rossin FM, Zago MMF Intervenção educativa para candidatos ao transplante de fígado. Rev Latino-Am. Enfermagem. 2013(fev);21(1):419-25

9. Mendes KDS, Galvão CM. Transplante de fígado: evidências para o cuidado de Enfermagem. Rev LatinoAm Enfermagem. 2008;16(5):915-22.

10. Carvalho DV, Salviano MEM, Carneiro RA, Santos FMM. Diagnóstico de Enfermagem de pacientes em pós-operatório de transplante hepático por cirrose etílica e não-etílica. Esc. Anna Nery. 2007;11(4):682-7.

11. Marandola PG, Matos SS, Mattia AL, Rocha AM, Silva JS, Resende MKB. Consulta de Enfermagem ao paciente em pré-transplante de fígado: elaboração de um protocolo. Rev Enferm Cent.-Oeste Min. 2011;1(3):324-31.

12. Aguiar MIF, Braga VAB. Sentimentos e expectativas de pacientes candidatos ao transplante de fígado. Rev. Eletr. Enf. 2011;13(3):413-21.

13. Anastácio LR, Pereira MCA, Vilela EG, Lima AS, Correia MITD .Excesso de peso em pacientes submetidos ao transplante hepático. Rev. Col. Bras. Cir. 2013;40(6):502-7 